\title{
CORRIGENDUM
}

\section{Disease status is a more reliable predictive factor than histology in lymphoma patients after reduced-intensity conditioning regimen and allo-SCT}

L Castagna, R Boubdallah, S Furst, D Coso, J El Cheikh, C Faucher, R Crocchiolo, A Granata, C Chabannon, C Lemarié, B Calmels, JM Boher, M Mohty and D Blaise

Bone Marrow Transplantation (2018) 53, 234; doi:10.1038/bmt.2018.1

Correction to: Bone Marrow Transplantation (2013) 48, 794-798; doi:10.1038/bmt.2012.225 published online June 2013
Following the publication of this article the author, M Mohty, noted that his name had been misspelt as M Mothy. This article is issued to correct the spelling of this name. 